\title{
Pola Asuh Autoritatif dan Kebiasaan Makan Anak Prasekolah
}

\author{
Yora Harlistyarintica ${ }^{\bowtie}$, Puji Yanti Fauziah ${ }^{2}$ \\ Pendidikan Anak Usia Dini, Universitas Negeri Yogyakarta \\ DOI: $\underline{10.31004 / o b s e s i . v 5 i 1.617}$
}

\begin{abstract}
Abstrak
Pola asuh autoritatif merupakan pola asuh yang memperhatikan kebutuhan anak termasuk dalam hal makan dengan memberikan dorongan, aturan, pilihan, serta bimbingan pada anak. Anak prasekolah sering mengalami masalah kesehatan berkaitan dengan masalah gizi yang disebabkan oleh kebiasaan makan anak. Kebiasaan makan yang buruk akan berpengaruh pada pertumbuhan dan perkembangan anak. Penelitian ini bertujuan untuk mendeskripsikan hubungan pola asuh autoritatif dengan kebiasaan makan anak prasekolah. Metode penelitian menggunakan kajian pustaka. Teknik analisis data yang digunakan dengan teknik analisis deskriptif. Hasil penelitian menunjukkan bahwa pola asuh autoritatif memiliki dampak positif bagi kebiasaan makan anak prasekolah. Orang tua yang menerapkan pola asuh autoritatif didapatkan anak yang memiliki kebiasaan makan yang baik seperti anak memiliki kualitas makan yang terjaga dengan mengkonsumsi makanan sehat dan bergizi seperti buah dan sayur serta sedikit kemungkinan untuk dapat mengalami kelebihan berat badan dan obesitas. Akhirnya, anak yang berada dalam pola asuh autoritatif dapat memiliki pola hidup sehat.
\end{abstract}

Kata Kunci: pola asuh autoritatif; kebiasaan makan; anak prasekolah.

\begin{abstract}
Authoritative parenting is a pattern of parenting that pays attention to children's needs including in terms of eating by providing encouragement, rules, choices, and guidance to children. Preschoolers often experience health problems related to nutritional problems caused by children's eating habits. Bad eating habits will affect the growth and development of children. This study aims to describe the relationship between authoritative parenting and the eating habits of preschool children. The research method uses a literature review. The data analysis technique used is descriptive. The results showed that authoritative parenting has a positive impact on the eating habits of preschool children. Parents who apply authoritative parenting found that children who have good eating habits, such as children, have a quality diet that is maintained by consuming healthy and nutritious foods such as fruits and vegetables and is less likely to be overweight and obese. Finally, children who are in authoritative parenting can have a healthy lifestyle.
\end{abstract}

Keywords: authoritative parenting; eating habit; preschooler.

Copyright (c) 2020 Yora Harlistyarintica, Puji Yanti Fauziah

$\triangle$ Corresponding author:

Email Address : yoraharlistyarintica.2019@student.uny.ac.id ( Yogyakarta, Indonesia )

Received 25 June 2020, Accepted 10 August 2020, Published 6 September 2020 


\section{PENDAHULUAN}

Anak prasekolah adalah anak usia dini yang berusia sekitar 3-6 tahun. Pada masa ini, pertumbuhan dan perkembangan anak terus berlangsung. Aspek penting dalam perkembangan anak adalah kebiasaan makan (Santrock, 2016) dengan mengkonsumi makanan bergizi seimbang karena dapat mempengaruhi kehidupan selanjutnya (Choi et al., 2018). Namun, umumnya pada masa ini anak memiliki masalah kesehatan. Masalah kesehatan yang sering dialami anak-anak adalah masalah gizi yang disebabkan oleh kebiasaan makan anak. Masalah gizi pada anak prasekolah akan berdampak negatif bagi perkembangan kognitif, perilaku, kegiatan belajar di sekolah maupun kegiatan lainnya yang berpengaruh pada kehidupan berikutnya (Abdel-Rahman et al., 2017). Berdasarkan data Riset Kesehatan Dasar Indonesia tahun 2018 bahwa presentase status gizi buruk dan gizi kurang pada balita dengan Indeks Berat Badan menurut Umur (BB/U) yang mengalami sebesar 3,9\% dan 13,8\%; status gizi sangat pendek dan pendek pada balita dengan Indeks Tinggi Badan menurut Umur (TB/U) yang mengalami sebesar 11,5\% dan 19,3\%; status gizi sangat kurus dan kurus pada balita dengan Indeks Berat Badan menurut Tinggi Badan (BB/TB) yang mengalami sebesar 3,5\% dan 6,7\% (Depkes RI, 2011). Tingginya kasus gizi di Indonesia menunjukkan bahwa anak prasekolah dalam kebiasaan mengkonsumsi makanan yang mengandung gizi seimbang masih membutuhkan dukungan keluarga terutama orang tua.

Pola asuh orang tua yang berkaitan dengan makanan merupakan strategi yang dilakukan oleh orang tua berdasarkan tujuan pada waktu mengkonsumsi makanan berat maupun makanan ringan (Lopez et al., 2018), di mana tujuan pengasuhan merujuk pada hasil yang diinginkan orang tua dalam mempertimbangkan masa depan (Chang \& Lee, 2017) melalui kebiasaan makan anak agar mampu menunjang pertumbuhan dan perkembangan. Pola asuh yang sesuai merupakan faktor keberhasilan dalam menentukan hasil yang baik bagi anak pada tahun-tahun awal kehidupan dan selanjutnya (Kooraneh \& Amirsardari, 2015). Konsep pola asuh yang paling luas digunakan dalam studi perkembangan anak adalah konsep pola asuh dari Baumrind yang menggolongkan pola asuh menjadi beberapa gaya yaitu autoritatif/otoritatif, autortarian/otoriter, dan permisif (Lopez et al., 2018; Mensah \& Kuranchie, 2013; Yaffe, 2018).

Gaya pengasuhan yang autoritatif ditandai dengan orang tua memiliki bimbingan sistematis yang memadukan keinginan anak (Lopez et al., 2018) dengan cara mendorong anak untuk menjadi anak mandiri, tetapi tetap memiliki batasan dan mengendalikan tindakannya (Santrock, 2016). Gaya pengasuhan yang otoriter ditandai dengan orang tua memiliki aturan yang kaku, adanya penetapan disiplin yang ketat, sehingga tercipta masalah mendasar bagi aspek perkembangan anak (Kooraneh \& Amirsardari, 2015) seperti menjadikan anak sedih, mengalami kecemasan, dan penakut (Santrock, 2016). Gaya pengasuhan yang permisif ditandai dengan orang tua memiliki kehangatan dan tanggung jawab, namun tidak memberlakukan aturan terhadap perilaku anak (Mensah \& Kuranchie, 2013) karena memiliki harapan rendah pada anak yang digantikan dengan kasih sayang berlebih serta menyedikitkan hukuman (Kooraneh \& Amirsardari, 2015).

Gaya makan dapat diartikan sebagai bagian dari gaya pengasuhan khusus selama waktu makan (Shloim et al., 2015) yang berdampak pada kebiasaan makan anak bahwa gaya makan orang tua dapat menentukan banyaknya makanan yang dikonsumsi oleh anak-anak (Lipowska et al., 2018). Dengan demikian, gaya pengasuhan orang tua khusunya pada gaya makan dapat meningkatkan atau mengurangi kebiasaan anak dalam mengkonsumsi makanan sehat dan bergizi (Arredondo et al., 2018). Misalnya gaya makan autoritatif, orang tua mendorong anak untuk makan dengan menggunakan aturan yang jelas dan responsif disertai adanya negosiasi dan pujian pada anak, sedangkan gaya makan otoriter, orang tua mendorong anak untuk makan, namun menggunakan aturan orang tua tanpa adanya negosiasi dengan anak serta adanya hukuman bagi anak yang melanggar aturan makan (Shloim et al., 2015). 
Memahami praktik pengasuhan yang berhubungan dengan kegiatan makan adalah penting bagi orang tua, karena dapat mengetahui kualitas makanan yang dikonsumsi oleh anak sejak dini. Selain itu, pentingnya kebiasaan makan yang sehat dan bergizi sejak dini sebagai upaya pencegahan terhadap penyakit kronis tidak menular saat dewasa kelak (Andreoli et al., 2018). Oleh sebab itu, peneliti ingin mengkaji lebih dalam berkaitan dengan praktik pengasuhan terhadap kebiasaan makan anak prasekolah. Khususnya pada praktik pengasuhan autoritatif.

\section{Pola Asuh Autoritatif}

Pola asuh autoritatif adalah salah satu jenis pola asuh yang dikembangkan oleh Baumrind. Pola asuh autoritatif merupakan perpaduan antara perilaku menuntut dan responsif yang memberikan dampak positif bagi perkembangan anak (Jackson et al., 1998) seperti pada aspek perkembangan kognitif maupun sosial (Pratt et al., 1988). Orang tua yang menerapkan pola asuh autoritatif lebih peduli pada kebutuhan anak, yang ditandai dengan menyeimbangkan antara komunikasi dan penetapan aturan serta memberikan dukungan dan mengasuh anak (Pratt et al., 1988).

Orang tua autoritatif juga menerapkan hukuman, namun lebih diminimalisir yang digantikan dengan adanya komunikasi dalam mencari solusi bersama, karena sangat menghargai keputusan anak (Larzelere et al., 2013) sehingga anak memiliki kebebasan untuk berpendapat (Hasanah \& Sugito, 2020). Dapat dikatakan, orang tua yang menerapkan pola asuh autoritatif bersikap rasional dalam bertindak (Sofiani et al., 2020), lebih terbuka terhadap anak, karena adanya keinginan yang ingin diterapkan yaitu agar anak lebih memahami dan mampu menerapkan perilaku yang sesuai dengan aturan berlaku, memberikan stimulus pada anak agar bisa menghargai orang lain, dan mengajarkan kedisiplinan dengan cara yang berbeda pada anak (Larzelere et al., 2013).

Anak-anak dari orang tua yang autoritatif didapatkan memiliki anak dengan perkembangan yang baik seperti memiliki percaya diri, mandiri, memiliki kontrol diri dalam berperilaku, memiliki kematangan sosial, dan prestasi akademik yang cukup tinggi (Jackson et al., 1998) serta memiliki gaya hidup yang positif seperti cenderung mengkonsumi makanan yang sehat dan bergizi (Johnson et al., 2012).

\section{Kebiasaan Makan Anak Prasekolah}

Kebiasaan makan merupakan salah satu kebiasaan yang dilakukan manusia dalam memenuhi kebutuhan hidupnya yang meliputi sikap, kepercayaan, serta dalam hal memilih makanan yang akan dikonsumsinya (Khomsan et al., 2007; Putri Prasasti, 2018) secara berulang kali. Kebiasaan makan orang tua akan berpengaruh pada kebiasaan makan anaknya termasuk pada anak prasekolah.

Anak prasekolah sudah memiliki sifat menjadi konsumen aktif dengan menunjukkan kemampuannya dalam memilih makanan yang menjadi pilihannya atau yang disukainya untuk dikonsumsi (Purwani et al., 2013; Rahayu, 2013). Orang tua khususnya ibu sangat penting dalam menanamkan kebiasaan makan pada anak prasekolah. Anak cenderung memiliki keterlibatan dalam mengambil keputusan makanan yang akan dikonsumsi anaknya (Lipowska et al., 2018). Ibu juga dapat melibatkan anak untuk memilih makanan sehat dan bergizi yang akan dikonsumsinya sehingga akan berpengaruh pada kebiasaan makan yang positif pada usia selanjutnya (Rahayu, 2013). Namun demikian, ayah juga dapat berkontribusi dalam menanamkan kebiasaan makan sehat dan bergizi pada anak dengan cara berbeda (Lipowska et al., 2018).

Kebiasaan mengkonsumsi makanan sehat dan bergizi sejak dini penting dilakukan karena dapat mengoptimalkan aspek perkembangan fisik dan kognitif anak sehingga berdampak pada kesehatan di usia berikutnya (Kastorini et al., 2019). Oleh sebab itu, baik ibu maupun ayah memiliki kontribusi penting pada kebiasaan makan anak prasekolah sehingga perlu memperhatikan dan menerapkan pola makan sehat dan bergizi secara berulang kali. 
Kebiasan tersebut dapat mempengaruhi pertumbuhan anak. Pertumbuhan anak merupakan pertambahan berat dan tinggi badan yang mencerminkan kondisi kesehatan dan gizinya (Suryani \& Haryono, 2018).

\section{METODOLOGI}

Jenis penelitian ini menggunakan kajian pustaka. Teknik analisis data yang digunakan dengan teknik analisis deskriptif. Langkah-langkah yang dilakukan dalam penelitian ini yaitu (Ramdhani et al., 2014): (1) Memilih topik yang akan dikaji; (2) Mencari dan memilih artikel yang sesuai atau relevan; (3) Melakukan analisis dan sintesis literatur yang dikaji; dan (4) Mengorganisasi penulisan kajian.

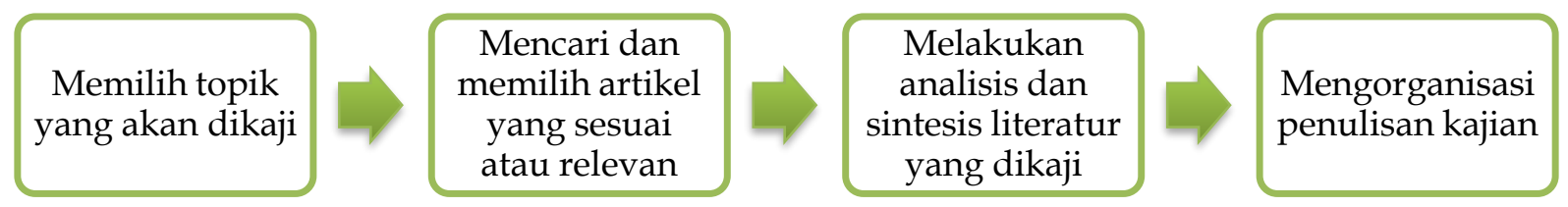

Gambar 1. Langkah-langkah Kajian Pustaka

Fokus penelitian yang dikaji terkait praktik pola asuh autoritatif dan kebiasaan makan anak prasekolah. Data yang digunakan merupakan data sekunder yang berasal dari artikel jurnal ilmiah, textbook, dan sumber-sumber lainnya yang relevan dengan penelitian ini. Adapun pertanyaan yang menjadi fokus dari penelitian ini yaitu: (1) Bagaimanakah penerapan pola asuh autoritatif dalam hal pemberian makan bagi anak prasekolah?; (2) Apa dampak dari penerapan pola asuh autoritatif bagi kebiasaan makan anak prasekolah?.

\section{HASIL DAN PEMBAHASAN}

Pola asuh orang tua sebagai salah satu faktor penentu dalam membiasakan anak dalam mengkonsumsi makanan sehat dan bergizi sejak usia dini. Pentingnya membiasakan anak untuk mengkonsumsi makanan sehat dan bergizi berguna bagi anak agar dapat memahami pentingnya gizi bagi tubuh, sehingga memberikan pengetahuan anak dalam mengkonsumsi makanan sehat sehari-hari. Mengingat, masa prasekolah adalah masa yang kritis dalam membantu anak mengadopsi perilaku hidup sehat (Hansen et al., 2015) salah satunya melalui kebiasaan makan karena perilaku yang ditetapkan pada masa kritis cenderung akan bertahan dari masa prasekolah hingga dewasa kelak (Arlinghaus et al., 2018). Orang tua juga pendorong langsung kualitas makanan anak, dan akibatnya memiliki tanggung jawab untuk membangun lingkungan makan anak dengan cara yang baik (Savage et al., 2007). Mengasuh anak memerlukan kemampuan secara interpersonal dan tuntutan emosional (Santrock, 2016) dalam memenuhi kebutuhan dasar anak seperti dalam pemenuhan gizi.

Konsep gaya pengasuhan umum telah didefinisikan sebagai sikap interaksi antara orang tua terhadap anak yang menciptakan ekspresi emosional di mana perilaku orang tua diungkapkan dalam bentuk praktik pengasuhan (Darling \& Steinberg, 1993). Praktik pengasuhan yang sesuai dengan tujuan misalnya seperti menciptakan peraturan di rumah dalam mengkonsumsi makanan sehat dan bergizi. Para orang tua dalam mewujudkan suatu harapan sesuai tujuannya dengan mencoba mendidik dan mengasuh anak-anaknya menggunakan gaya yang dianggap paling baik. Gaya orang tua khususnya dalam pemenuhan gizi saat memberi makan pada anak akan mempengaruhi hubungan anak dengan kegiatan makan di masa dewasa. Kegiatan makan tidak hanya berguna untuk memenuhi kebutuhan energi dalam tubuh saja, melainkan berfungsi juga sebagai kegiatan dalam melatih kemandirian anak serta interaksi antara anak dengan orang tua maupun keluarga. Terdapat beberapa tipe gaya pengasuhan yang dapat diadopsi oleh orang tua, salah satunya adalah gaya pengasuhan autoritatif. Berdasarkan hasil kajian pustaka dari berbagai sumber ilmiah 
yang relevan, maka penelitian ini mengkaji terkait gaya pengasuhan autoritatif dan berbagai dampak positifnya bagi kebiasaan makan anak. Selain itu, juga sebagai panduan berupa cara maupun saran bagi orang tua dalam menerapkan gaya pengasuhan autoritatif bagi anak sehingga anak memiliki kebiasaan mengkonsumsi makanan sehat dan bergizi sejak dini.

Pola asuh autoritatif adalah salah satu bentuk pola asuh yang memberikan kebebasan pada anak, tetapi tetap menerapkan batasan yang jelas dan mengendalikan tindakan yang dilakukan anak. Orang tua dalam menerapkan pola asuh autoritatif lebih mengutamakan kepentingan anak daripada kepentingan dirinya. Orang tua dalam mengarahkan perilaku anak juga menyesuaikan dengan kebutuhan anak yang tujuannya adalah agar anak memiliki pengetahuan, sikap, dan keterampilan yang dibutuhkan di masa yang akan datang sehingga kepribadian anak akan terbentuk sesuai dengan yang diharapkan.

Dalam hal pemberian makan, pola asuh autoritatif dapat dikatakan sebagai pola asuh yang paling seimbang dan sehat jika diterapkan pada anak yang sedang dalam masa golden age. Hal ini dikarenakan orang tua dalam memberikan makan pada anak dengan cara menentukan menu makanan yang akan dikonsumsi oleh anak, namun tetap memberikan kesempatan pada anak untuk memilih makanan yang menjadi pilihannya atau disukainya dengan pengawasan (Yumni \& Wijayanti, 2017). Orang tua dalam mengasuh anak dengan memberikan batasan pada pilihan makan, juga dengan memberikan bimbingan dan pola berkaitan dengan makanan yang dikonsumsi sehingga akan memudahkan pembentukan kebiasaan makan yang baik sejak dini (Grolnick \& Pomerantz, 2009). Adanya komunikasi orang tua dengan anak perihal makan berperan efektif dalam mengontrol asupan makan yang akan dikonsumsi oleh anak sehingga pemenuhan gizi anak terpenuhi dan anak tumbuh dan berkembang secara lebih ideal (Mohammad, 2000; Tridhonanto, 2014). Dengan kata lain, bahwa orang tua dengan pola asuh autoritatif berperan aktif dalam mendorong anak untuk makan yang disertai membimbing anak dalam hal makan.

Berdasarkan hasil penelitian yang dilakukan oleh Patrick et al. (2005) bahwa orang tua yang menerapkan pola asuh autoritatif cenderung memberikan makanan yang lebih sehat sehingga anak terbiasa mengkonsumsi susu, buah, dan sayuran. Penelitian yang dilakukan oleh oleh Blisset (2011) menunjukkan cara yang dilakukan orang tua dalam hal pemberian makan dengan gaya autoritatif yang dapat meningkatkan konsumsi buah dan sayur pada anak yaitu dengan menyediakan buah dan sayur di rumah, membatasi makanan ringan yang tidak sehat, orang tua selalu memberikan contoh, dan mendorong anak untuk mencoba mengkonsumsi buah dan sayuran pada anak, sehingga anak terbiasa untuk mengkonsumsi makanan yang sehat dan bergizi.

Dampak positif yang didapatkan dengan mengkonsumsi buah dan sayuran telah banyak dilaporkan bahwa berdampak bagi kesehatan mental anak-anak hingga dewasa (Choi et al., 2018). Hal ini disebabkan karena buah dan sayuran mengandung banyak unsur gabungan dari beragam vitamin, mineral, maupun antioksidan yang sangat dibutuhkan anak pada pada masa pertumbuhan dan perkembangan (Bean, 2007). Penting bagi orang tua untuk selalu memperhatikan asupan gizi yang dibutuhkan oleh anak di masa golden age.

Sejalan dengan hasil penelitian tersebut, penelitian yang dilakukan oleh Kesuma et al. (2015) juga menyarankan agar dalam menerapkan pola asuh yang berkaitan dengan kegiatan makan anak dengan cara seperti memberikan perhatian penuh kepada anak dengan menyediakan makanan yang sehat dan bergizi, memberikan contoh kepada anak dalam mengkonsumsi makanan yang sehat dan bergizi, memberikan kesempatan pada anak untuk ikut terlibat dalam menyiapkan dan memilih makanan yang menjadi pilihannya atau disukainya, dan mengontrol makanan yang dikonsumsi anak. Apabila orang tua dapat menerapkan pola asuh tersebut, maka berdasarkan hasil penelitian yang dilakukan oleh Sleddens et al. (2011) akan didapatkan anak yang lebih sehat yang ditunjukkan dengan anak terbiasa mengkonsumsi makanan sehat dan lebih aktif secara fisik jika dibandingkan dengan anak yang dibesarkan dari gaya pengasuhan lainnya. Hasil penelitian tersebut juga dipertegas oleh hasil penelitian yang dilakukan oleh Shloim et al. (Shloim et al., 2015) bahwa dengan 
menerapkan pola asuh autoritatif terbukti dapat mengarahkan asupan makanan yang lebih sehat sehingga akan membantu mencegah kelebihan berat badan dan obesitas pada anak. Anak cenderung memiliki berat badan normal sehingga aspek perkembangan anak dapat terstimulasi secara lebih optimal.

Pola asuh autoritatif cenderung dikaitkan memiliki dampak positif bagi kebiasaan makan anak prasekolah karena lebih banyak menggunakan responsive feeding. Terdapat lima prinsip utama responsive feeding yang dimaksud yaitu (Lukitasari, 2020): (1) Orang tua ikut terlibat saat kegiatan makan dengan cara menyuapi anak atau membantu anak untuk makan sendiri sehingga kemandirian anak juga akan terbentuk; (2) Orang tua dalam memberi makan pada anak disertai bimbingan yang dilakukan secara perlahan, penuh kesabaran, dan mendorong anak untuk makan; (3) Orang tua peduli akan respon anak terhadap penolakan makan yang dilakukan; (4) Orang tua dalam memberi makan anak dengan menyediakan lingkungan yang aman; dan (5) Saat kegiatan makan adalah waktu yang tepat untuk belajar dan menjalin interaksi dengan penuh kasih sayang antara orang tua terhadap anaknya. Hubungan yang terjalin antara orang tua dan anak akan semakin harmonis saat kegiatan makan.

Berdasarkan uraian yang telah dipaparkan bahwa pola asuh autoritatif berdampak positif pada kebiasaan makan anak prasekolah. Penerapan pola asuh autoritatif akan berpotensi memunculkan sejumlah kebiasaan makan yang baik pada diri anak sejak dini seperti: (1) Anak cenderung mengkonsumsi makanan sehat dan bergizi; (2) Anak cenderung memiliki jadwal makan yang waktunya telah disepakati bersama dengan orang tua sehingga tidak akan menghambat anak dalam mengenali kondisi lapar maupun kenyang; (3) Kegiatan makan dalam suasana yang tidak penuh tekanan cenderung akan membuat anak memiliki berat badan yang normal; (4) Anak ketika mendapatkan akses pada jenis-jenis makanan yang dilarang oleh orang tua cenderung tidak akan makan berlebihan karena dalam membatasi makan, orang tua selalu memberikan penjelasan pada anak; dan (5) Anak akan antusias terhadap makanan dan kegiatan makan karena orang tua membangun suasana yang menyenangkan.

Akhirnya anak yang berada dalam pola asuh autoritatif dapat memiliki pola hidup sehat yang berdampak pada kebiasaan anak dalam mengkonsumsi makanan sehat dan bergizi. Hal ini akan berpengaruh besar dalam mengoptimalkan pertumbuhan dan perkembangan anak. Lebih jelasnya penerapan pola asuh autoritatif dapat memberikan dampak positif bagi kebiasaan makan anak prasekolah disajikan dalam bentuk bagan berikut ini: 


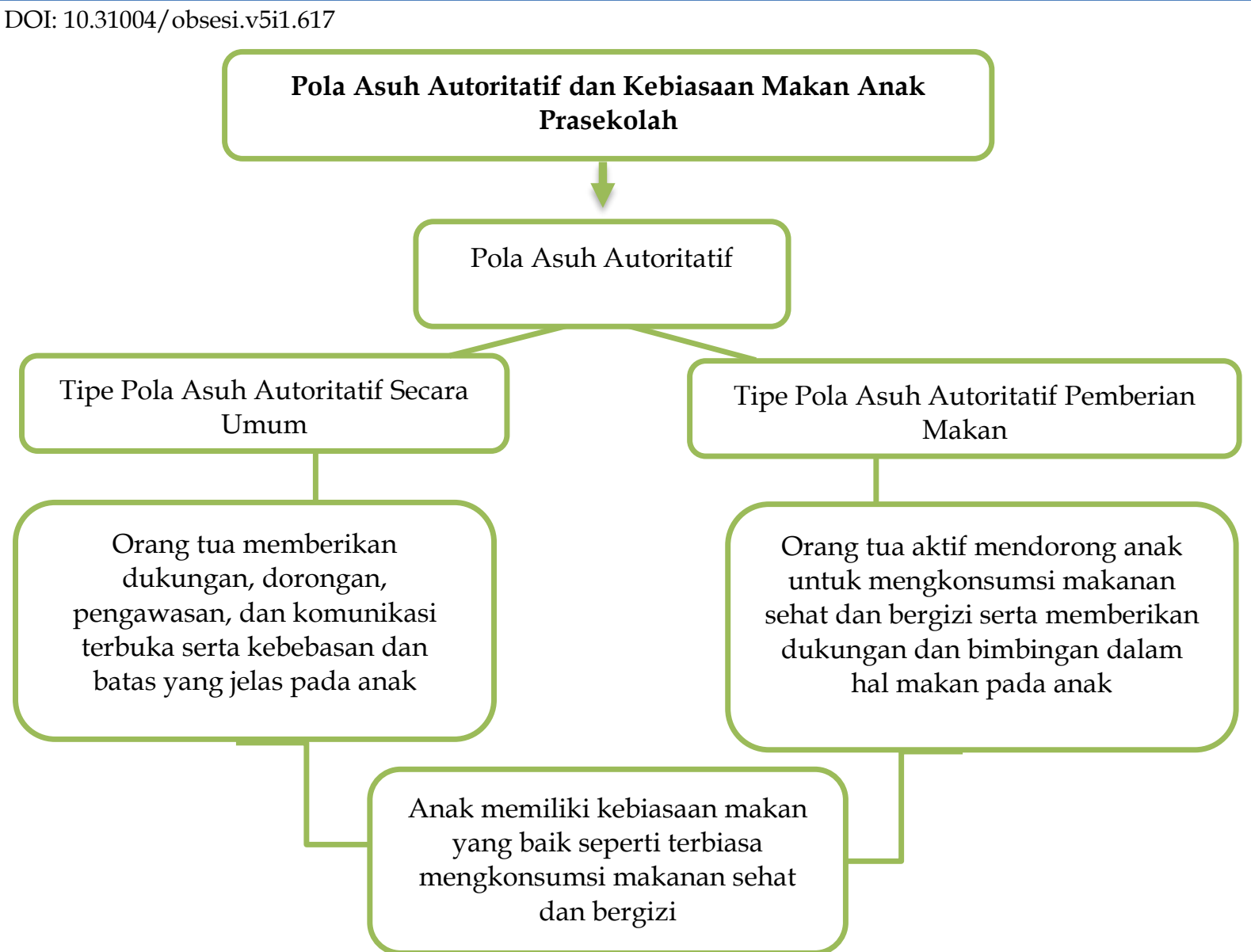

Gambar 2. Bagan Sintesa Kajian Pola Asuh Autoritatif dan Kebiasaan Makan Anak Prasekolah

\section{SIMPULAN}

Pola asuh autoritatif adalah pola asuh yang seimbang dan sehat serta berdampak positif bagi pertumbuhan dan perkembangan anak prasekolah. Dalam hal pemberian makan, orang tua yang menerapkan pola asuh autoritatif peduli akan kebutuhan gizi anak sehingga selalu berusaha menyediakan makanan yang sehat dan bergizi. Orang tua selalu mengontrol makan anak dengan cara mengatur menu makan yang akan dikonsumsi anak, memberikan contoh untuk mengkonsumsi makanan sehat dan bergizi, tetapi anak juga diberikan kebebasan dalam memilih makanan yang disukainya. Anak memiliki berat badan sehat dan sedikit kemungkinan untuk dapat mengalami kelebihan berat badan dan obesitas karena anak juga lebih aktif secara fisik.

\section{UCAPAN TERIMAKASIH}

Penulis mengucapkan terimakasih kepada dosen pembimbing atas bimbingannya maka artikel ini dapat tersusun serta kepada tim Jurnal Obsesi sehingga artikel ini dapat terpublikasikan.

\section{DAFTAR PUSTAKA}

Abdel-Rahman, T. A., Kamal, N. N., El-Dessouki, K. H., \& AbdAllah, A. A. (2017). Assessment of Nutritional Status and Cognitive Development of Preschool Children at Minia Governorate, Egypt. Canadian Journal of Clinical Nutrition, 5(1), 72-94. https://doi.org/10.14206/canad.j.clin.nutr.2017.01.08

Andreoli, C. S., Ribeiro-Vieira, S. A., Fonsêca, P. C. de A., Moreira, A. V. B., Ribeiro, S. M. R., \& Franceschini, S. do C. C. (2018). Markers of healthy eating habits, water intake, and constipation in children between 4 and 7 years of age. Revista de Nutricao, 31(4), 363372. https:// doi.org/10.1590/1678-98652018000400002 
Arlinghaus, K. R., Vollrath, K., Hernandez, D. C., Momin, S. R., O'Connor, T. M., Power, T. G., \& Hughes, S. O. (2018). Authoritative parent feeding style is associated with better child dietary quality at dinner among low-income minority families. American Journal of Clinical Nutrition, 108(4), 730-736. https:// doi.org/10.1093/ajcn/nqy142

Arredondo, E. M., Ayala, G. X., Soto, S., Slymen, D. J., Horton, L. A., Parada, H., Campbell, N., Ibarra, L., Engelberg, M., \& Elder, J. P. (2018). Latina mothers as agents of change in children's eating habits: Findings from the randomized controlled trial Entre Familia: Reflejos de Salud 11 Medical and Health Sciences 1117 Public Health and Health Services 11 Medical and Health Sciences 1111 Nutrit. International Journal of Behavioral Nutrition and Physical Activity, 15(1), 1-11. https:/ / doi.org/10.1186/s12966-018-0714-0

Bean, A. (2007). Healthy Eating for Kids: Over 100 Meal Ideas, Recipes and Healthy Eating Tips for Children (2nd ed.). A \& C Black.

Blissett, J. (2011). Relationships between parenting style, feeding style and feeding practices and fruit and vegetable consumption in early childhood. Appetite, 57(3), 826-831. https:/ / doi.org/10.1016/j.appet.2011.05.318

Chang, E. S., \& Lee, B. (2017). Parenting goals and perceived shared and non-shared agency among kirogi mothers of a youth. International Journal of Adolescence and Youth, 22(4), 470-483. https:// doi.org/10.1080/02673843.2016.1245149

Choi, E. B., Lee, J. E., \& Hwang, J.-Y. (2018). Fruit and Vegetable Intakes in Relation to Behavioral Outcomes Associated with a Nutrition Education Intervention in Preschoolers. Nutrition Research and Practice, 12(6), 521-526. https:/ / doi.org/10.4162/nrp.2018.12.6.521

Darling, N., \& Steinberg, L. (1993). Parenting Style as Context: An Integrative Model. Psychological Bulletin, 113(3), 487-496. https:/ / doi.org/10.1037/0033-2909.113.3.487

Depkes RI. (2011). Profil Kesehatan Indonesia Tahun 2011. In R. Kurniawan, Yudianto, B. Hardhana, \& T. Siswanti (Eds.), Kementrian Kesehatan Republik Indonesia. Kementerian Kesehatan RI.

Grolnick, W. S., \& Pomerantz, E. M. (2009). Issues and challenges in studying parental control: Toward a new conceptualization. Child Development Perspectives, 3(3), 165-170. https:// doi.org/10.1111/j.1750-8606.2009.00099.x

Hansen, A. R., Alfonso, M. L., Hackney, A. A., \& Luque, J. S. (2015). Preschool Children's SelfReports of Fruit and Vegetable Knowledge, Preference, and Messages Encouraging Consumption. Journal of School Health, 85(6), 355-364. https:/ / doi.org/10.1111/josh.12260

Hasanah, N., \& Sugito, S. (2020). Analisis Pola Asuh Orang Tua terhadap Keterlambatan Bicara pada Anak Usia Dini. Jurnal Obsesi: Jurnal Pendidikan Anak Usia Dini, 4(2), 913. https:// doi.org/10.31004/obsesi.v4i2.456

Jackson, C., Henriksen, L., \& Foshee, V. A. (1998). The Authoritative Parenting Index: Predicting Health Risk Behaviors among Children and Adolescents. Health Education and Behavior, 25(3), 319-337. https://doi.org/10.1177/109019819802500307

Johnson, R., Welk, G., Saint-Maurice, P. F., \& Ihmels, M. (2012). Parenting styles and home obesogenic environments. International Journal of Environmental Research and Public Health, 9(4), 1411-1426. https:// doi.org/10.3390/ijerph9041411

Kastorini, C. M., Critselis, E., Zota, D., Coritsidis, A. L., Nagarajan, M. K., Papadimitriou, E., Belogianni, K., Benetou, V., \& Linos, A. (2019). National Dietary Guidelines of Greece for children and adolescents: A tool for promoting healthy eating habits. Public Health Nutrition, 22(14), 2688-2699. https:// doi.org/10.1017/S1368980019001034

Kesuma, A., Novayelinda, R. \& Sabrina, F. (2015). Faktor - Faktor Yang Berhubungan Dengan Perilaku Kesulitan Makan Anak Prasekolah (Doctoral dissertation, Riau University). Faktor - Faktor Yang Berhubungan Dengan Perilaku Kesulitan Makan Anak Prasekolah (Doctoral Dissertation, Riau University)., 2(2), 953-961.

Khomsan, A., Anwar, F., Sukandar, D., Riyadi, H., \& Mudjajanto, E. S. (2007). Studi tentang 
DOI: 10.31004/obsesi.v5i1.617

Pengetahuan Gizi Ibu dan Kebiasaan Makan pada Rumah Tangga di Daerah Dataran Tinggi dan Pantai. Jurnal Gizi Dan Pangan, 1(1), 23-28. https://doi.org/10.25182/jgp.2006.1.1.23-28

Kooraneh, A. E., \& Amirsardari, L. (2015). Predicting early maladaptive schemas using Baumrind's parenting styles. Iranian Journal of Psychiatry and Behavioral Sciences, 9(2), 26-30. https:// doi.org/10.5812/ijpbs.952

Larzelere, R. E., Cox Jr, R. B., \& Mandara, J. (2013). Responding to Misbehavior in Young Children: How Authoritative Parents Enhance Reasoning with Firm Control. In Authoritative parenting: Synthesizing nurturance and discipline for optimal child development. (pp. 89-111). American Psychological Association. https:/ / doi.org/10.1037/13948-005

Lipowska, M., Lipowski, M., Jurek, P., Jankowska, A. M., \& Pawlicka, P. (2018). Gender and body-fat status as predictors of parental feeding styles and children's nutritional knowledge, eating habits and behaviours. International Journal of Environmental Research and Public Health, 15(5), 852. https://doi.org/10.3390/ijerph15050852

Lopez, N. V, Schembre, S., Belcher, B. R., O'Connor, S., Maher, J. P., Arbel, R., Margolin, G., \& Dunton, G. F. (2018). Parenting styles, food-related parenting practices, and children's healthy eating: A meditation analysis to examine relationships between parenting and child diet. Appetite, 128, 205-213. https:/ / doi.org/10.1016/j.appet.2018.06.021

Lukitasari, D. (2020). Hubungan Pola Asuh Orang Tua dengan Perilaku Picky Eater pada Anak Usia Prasekolah. Sehat Masada, 14(1), 73-80. https:/ / doi.org/10.38037/jsm.v14i1.127

Mensah, M. K., \& Kuranchie, A. (2013). Influence of Parenting Styles on the Social Development of Children. Academic Journal of Interdisciplinary Studies, 2(3), 123-129. https://doi.org/10.5901/ajis.2013.v2n3p123

Mohammad, S. (2000). Pola Asuh Orang Tua Dalam Membantu Anak Mengembangkan Disiplin Diri. Rineka Cipta.

Patrick, H., Nicklas, T. A., Hughes, S. O., \& Morales, M. (2005). The benefits of authoritative feeding style: Caregiver feeding styles and children's food consumption patterns. Appetite, 44(2), 243-249. https://doi.org/10.1016/j.appet.2002.07.001

Pratt, M. W., Kerig, P., Cowan, P. A., \& Cowan, C. P. (1988). Mothers and Fathers Teaching 3Year-Olds: Authoritative Parenting and Adult Scaffolding of Young Children's Learning. Developmental Psychology, 24(6), 832-839. https://doi.org/10.1037/00121649.24.6.832

Purwani, Erni, \& Mariyam. (2013). Pola Pemberian Makan Dengan Status Gizi Anak Usia 1 Sampai 5 Tahun Di Kabunan Taman Pemalang. Jurnal Keperawatan Anak, 1(1), 30-36. http:/ / download.portalgaruda.org/ article.php?article=98477\&val=5091

Putri Prasasti, H. (2018). Pengaruh Kebiasaan Makan Keluarga terhadap Status Gizi Anak di SDN Babak Sari-Kecamatan Dukun-Kabupaten Gresik (Studi Kasus). Jurnal Tata Boga, $8(1)$.

Rahayu, S. (2013). Kebiasaan Makan Anak Kecamatan Pulogadung. Journal of Chemical Information and Modeling, 1689-1699. https:// doi.org/10.1017/CBO9781107415324.004

Ramdhani, A., Ramdhani, M., \& Amin, A. (2014). Writing a Literature Review Research Paper: A step-by-step approach. International Journal of Basic and Applied Science, 3(01), 47-56.

Santrock, J. W. (2016). Children (13th ed.). McGraw-Hill Education.

Savage, J. S., Fisher, J. O., \& Birch, L. L. (2007). Parental influence on eating behavior: Conception to adolescence. Journal of Law, Medicine and Ethics, 35(1), 22-34. https://doi.org/10.1111/j.1748-720X.2007.00111.x

Shloim, N., Edelson, L. R., Martin, N., \& Hetherington, M. M. (2015). Parenting styles, feeding styles, feeding practices, and weight status in 4-12 year-old children: A systematic review of the literature. In Frontiers in Psychology (Vol. 6, Issue DEC, p. 1849). Frontiers. https://doi.org/10.3389/fpsyg.2015.01849 
Sleddens, E. F. C., Gerards, S. M. P. L., Thijs, C., De Vries, N. K., \& Kremers, S. P. J. (2011). General parenting, childhood overweight and obesity-inducing behaviors: A review. In International Journal of Pediatric Obesity (Vol. 6, Issues 2-2, pp. e12-e27). Wiley Online Library. https:/ / doi.org/10.3109/17477166.2011.566339

Sofiani, I. K., Mufika, T., \& Mufaro'ah, M. (2020). Bias Gender dalam Pola Asuh Orangtua pada Anak Usia Dini. Jurnal Obsesi: Jurnal Pendidikan Anak Usia Dini, 4(2), 766. https:// doi.org/10.31004/obsesi.v4i2.300

Suryani, N. A., \& Haryono, M. (2018). Improvement of the Logical Intelligence Through Media Kolak (Collage Numbers) Based on Local Wisdom on Early Childhood. Jurnal Obsesi : Jurnal Pendidikan Anak Usia Dini, 2(2), 253. https:// doi.org/10.31004/obsesi.v2i2.90

Tridhonanto, A. (2014). Mengembangkan Pola Asuh Demokratis. Elex Media Komputindo.

Yaffe, Y. (2018). Establishing Specific Links Between Parenting Styles and the S-Anxieties in Children: Separation, Social, and School. Journal of Family Issues, 39(5), 1419-1437. https:// doi.org/10.1177/0192513X17710286

Yumni, D. Z., \& Wijayanti, H. S. (2017). Perbedaan perilaku makan dan pola asuh pemberian makan antara balita gemuk dan non gemuk di Kota Semarang. Journal of Nutrition College, 6(1), 43. https:// doi.org/10.14710/jnc.v6i1.16892 